Supplement of Biogeosciences Discuss., 12, 7017-7053, 2015

http://www.biogeosciences-discuss.net/12/7017/2015/

doi:10.5194/bgd-12-7017-2015-supplement

(C) Author(s) 2015. CC Attribution 3.0 License.

(c) (i)

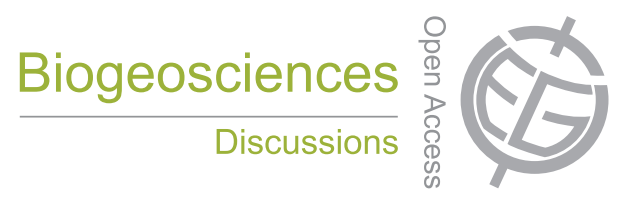

Supplement of

\title{
Methane distribution, flux, and budget in the East China Sea and Yellow Sea
}

M.-S. Sun et al.

Correspondence to: G.-L. Zhang (guilingzhang@ouc.edu.cn)

The copyright of individual parts of the supplement might differ from the CC-BY 3.0 licence. 


\section{Supplement}
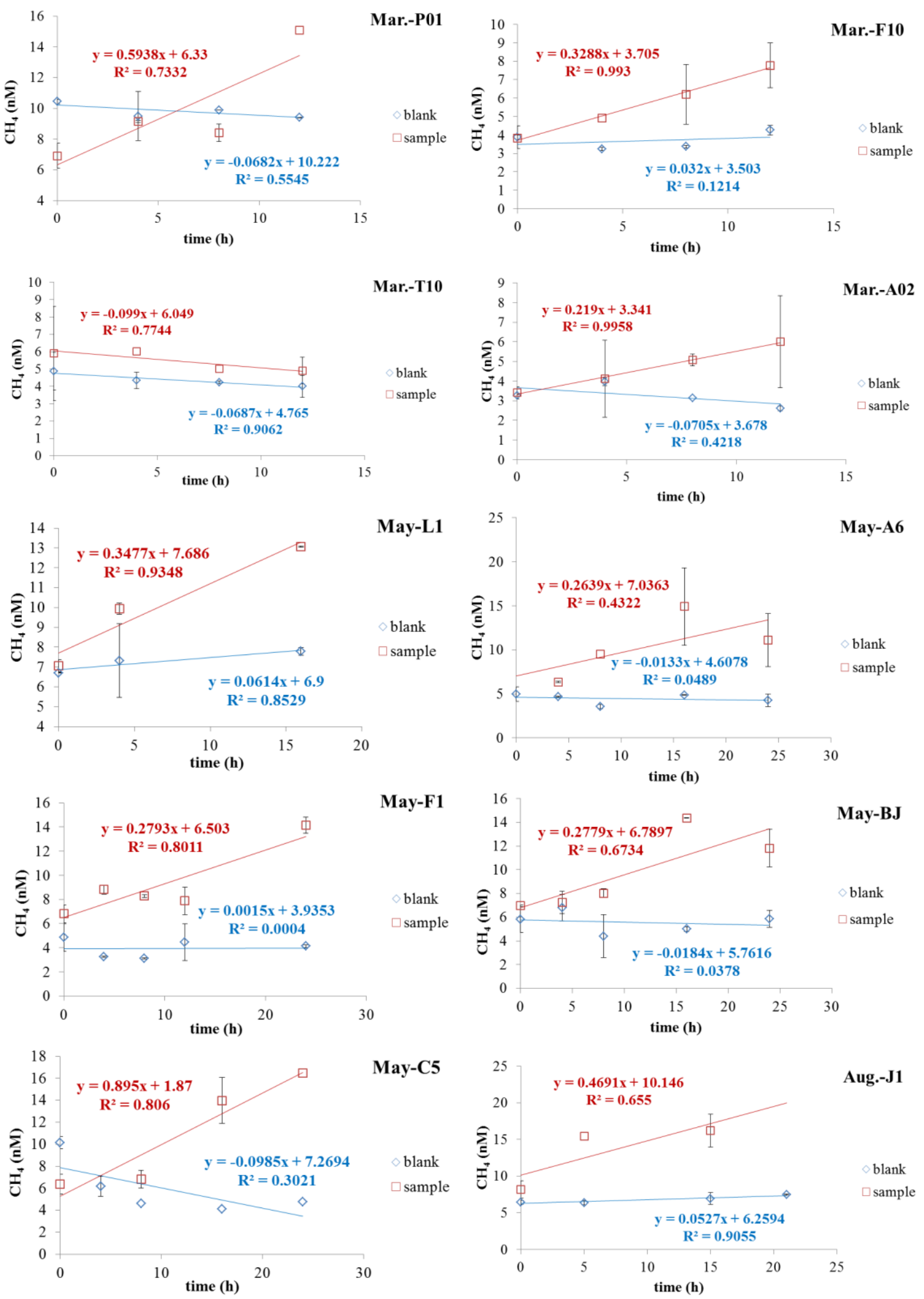

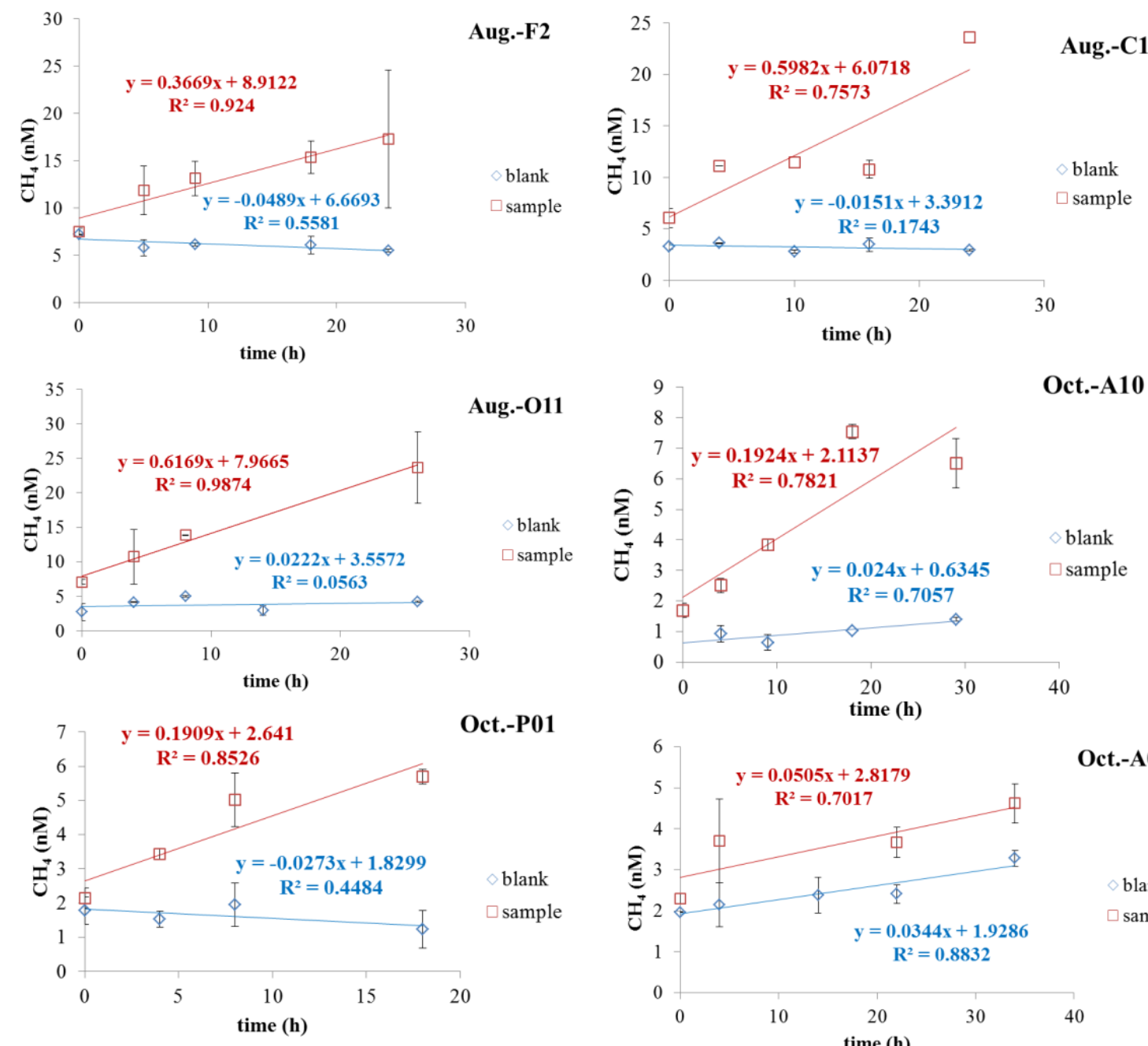

Oct.-P01
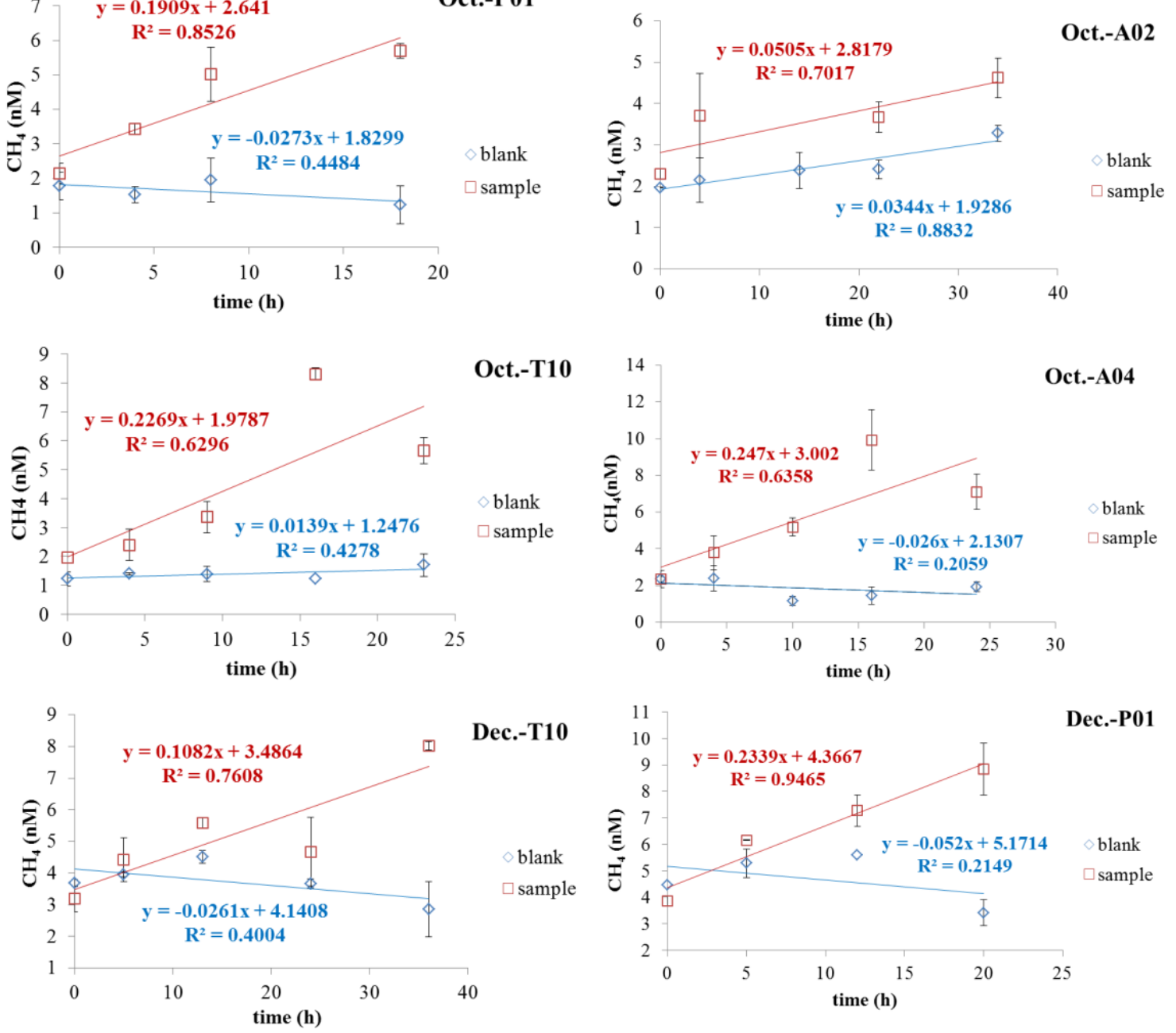

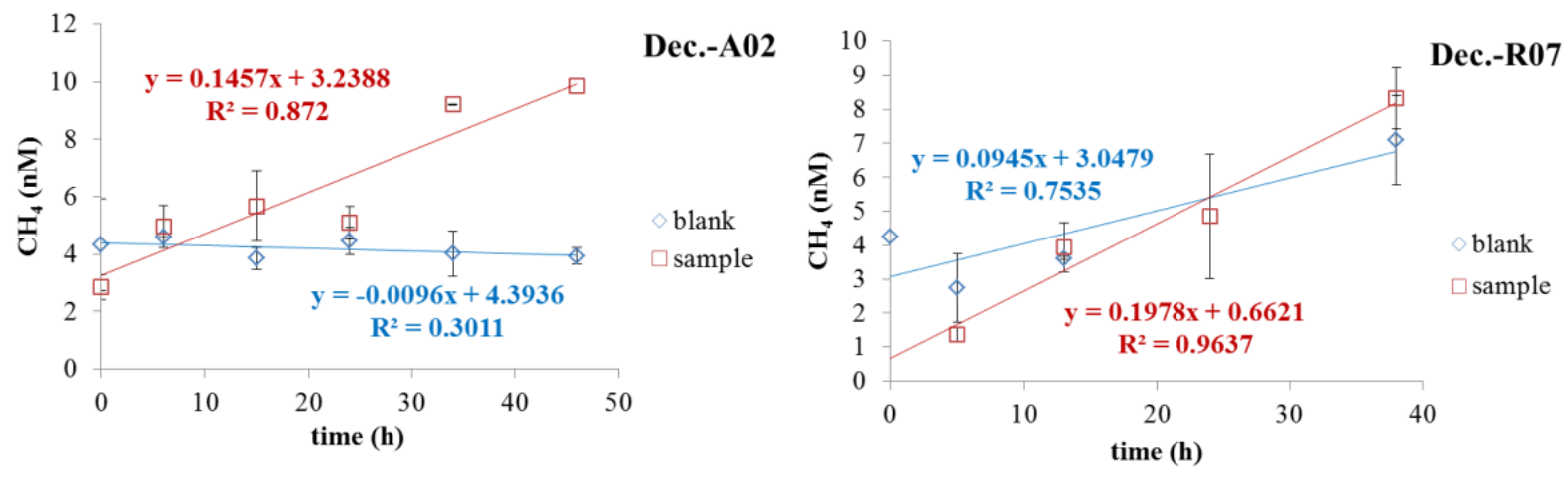

Fig. S1 Variation of $\mathrm{CH}_{4}$ concentration with time during sediment incubation experiments (Square: overlying water; diamond: control)
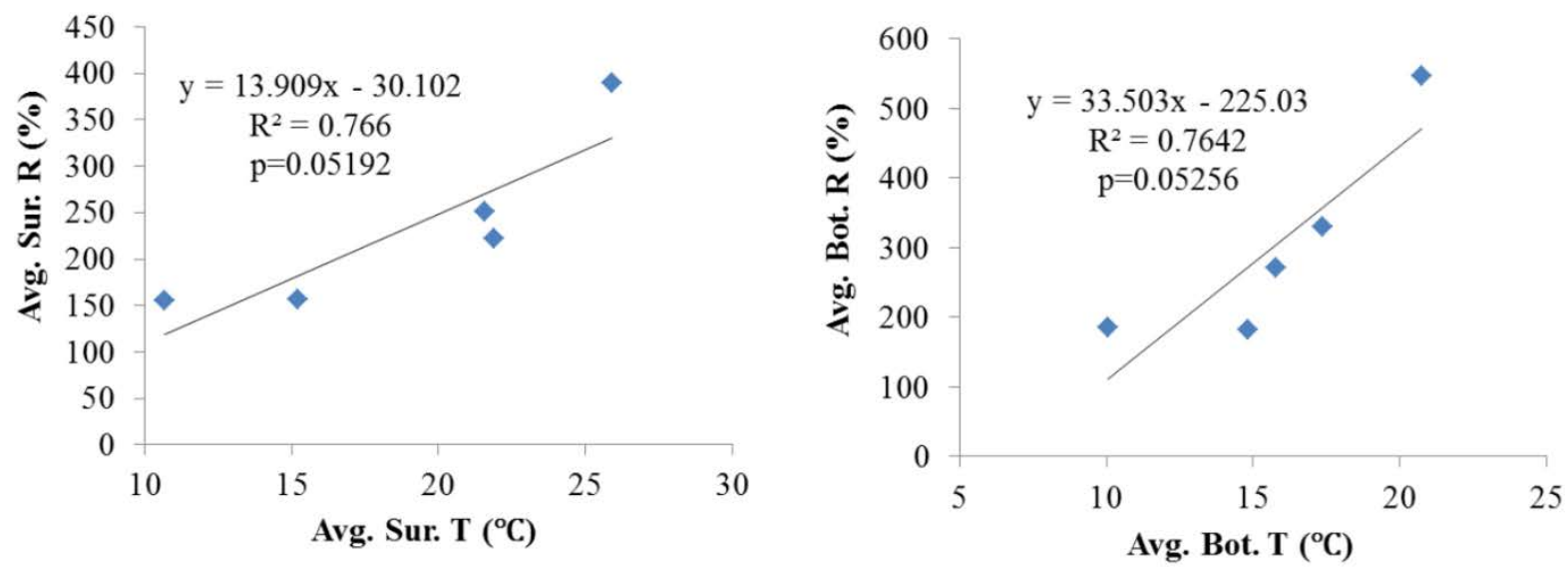

Fig. S2 The correlation between mean $\mathrm{CH}_{4}$ saturation and mean water temperature in surface and bottom water 